\title{
Moving from knowledge to practice: is it time to move from teaching evidence-based medicine (EBM) to knowledge translation competency?
}

\author{
Imad S. A. Hassan
}

Published online: 30 March 2013

(C) The Author(s) 2013. This article is published with open access at Springerlink.com

\section{Dear Sir,}

Since its arrival to the scene of medicine and despite its worldwide acceptance as a new paradigm in healthcare, the implementation of evidence has been extremely slow $[1,2]$. The latter was the primary driving force for the birth of the science of knowledge translation - the practical implementation of evidence [3]. The article by Widyahening et al. [4] is a welcome move for incorporating evidence-based medicine (EBM) in medical school curricula in developing countries. However, the emphasis should not be on teaching the science of EBM but rather on its practical application to patient care. As an educator of EBM, I strongly believe in including sessions on methods for redesigning daily routines to seamlessly incorporate EBM in the decision process, for example in morning meetings, ward rounds, outpatients, mortality case reviews etc. I also believe in including practical sessions on process change skills and in knowledge translation tools such as the use of integrated care pathways, order sets, other decision support tools, system redesign, etc. as part and parcel of EBM curricula. Emphasis on literature searching, appraisal, etc. without education and training on effective evidence-implementation tools may not be conducive to the recognition of the full objectives of the EBM science. On the whole, the curriculum should better be named Knowledge Translation Curriculum.

Open Access This article is distributed under the terms of the Creative Commons Attribution License which permits any use, distribution, and reproduction in any medium, provided the original author(s) and the source are credited.

\section{References}

\author{
I. S. A. Hassan $(\bowtie)$ \\ Department of Medicine 1443, King Abdulaziz Medical City, P.O. Box 22490, Riyadh 11426, \\ Kingdom of Saudi Arabia \\ email: imadsahassan@yahoo.co.uk
}


1. McGlynn E, Asch S, Adams J, et al. The quality of health care delivered to adults in the United States. N Engl J Med. 2003;348:2635-45.

2. Grol R. Successes and failures in the implementation of evidence-based guidelines for clinical practice. Med Care. 2001;39:II46-54.

3. Straus SE, Tetroe JM, Graham ID. Knowledge translation is the use of knowledge in health care decision making. J Clin Epidemiol. 2011;64(1):6-10.

4. Widyahening IS, van der Heijden GJ, Moy FM, van der Graaf Y, Sastroasmoro S, Bulgiba A. From west to east: experience with adapting a curriculum in evidence-based medicine. Perspect Med Educ. 2012;1(5-6):249-61.

\section{Author Biography}

Imad S. A. Hassan is a founding member and previously President of Sudan Evidence Based Medicine Association. He currently chairs the Knowledge Translation Committee of the Department of Medicine, King Abdulaziz Medical City at Riyadh, Kingdom of Saudi Arabia. He is actively involved in restructuring EBM training modules emphasizing knowledge translation training. 